\title{
Oxygen Saturation as a Predictor of Adverse Maternal Outcomes in Women with Preeclampsia
}

\author{
Alexandra L. Millman, BSc, ${ }^{1}$ Beth Payne, BSc, ${ }^{1,2}$ Ziguang Qu, BASc, ${ }^{1,2}$ \\ M. Joanne Douglas, MD, FRCPC, ${ }^{3}$ Jennifer A. Hutcheon, PhD, ${ }^{1,2,4}$ Tang Lee, MSc, ${ }^{1,2}$ \\ Laura A. Magee, MD, FRCPC, MSc, ${ }^{1,2,4,5}$ Keith R. Walley, MD, PhD, FRCPC, ${ }^{5}$ \\ Peter von Dadelszen, MBChB, DPhil, FRCSC1,2,4; for the PIERS \\ (Pre-eclampsia Integrated Estimate of RiSk) Study Group
}

1Department of Obstetrics and Gynaecology, University of British Columbia, Vancouver BC

${ }^{2}$ The CFRI Reproduction and Healthy Pregnancy Cluster, University of British Columbia, Vancouver BC

${ }^{3}$ Department of Anesthesiology, Pharmacology and Therapeutics, University of British Columbia, Vancouver BC

${ }^{4}$ School of Public and Population Health, University of British Columbia, Vancouver BC

${ }^{5}$ Department of Medicine, University of British Columbia, Vancouver BC

\section{Abstract}

Objective: We sought to determine the role of respiratory assessment by cardiorespiratory symptoms and/or oxygen saturation by pulse oximetry $\left(\mathrm{SpO}_{2}\right)$ in predicting adverse maternal outcomes in women admitted to hospital with preeclampsia.

Methods: These data derive from an international, prospective multicentre cohort study, PIERS (Pre-eclampsia Integrated Estimate of RiSk), which assesses predictors of adverse outcomes in women admitted to tertiary perinatal units with preeclampsia. Univariate and multivariate analyses of cardiorespiratory symptoms and pulse oximetry were performed to assess their ability to predict a combined adverse maternal outcome developed through international Delphi consensus.

Results: $\mathrm{SpO}_{2}$ successfully predicted adverse maternal outcomes; the area under the receiver-operator characteristic curve (AUC $\mathrm{ROC}$ ) was $0.71(95 \% \mathrm{Cl} 0.65$ to 0.77$)$. Combining the symptoms of chest pain and/or dyspnea with pulse oximetry improved this predictive ability (AUC ROC $0.73 ; 95 \% \mathrm{Cl} 0.67$ to 0.78 ). When $\mathrm{SpO}_{2}$ was stratified into risk groups using inflection points on the ROC curve, the highest risk group $\left(\mathrm{SpO}_{2} 90 \%\right.$ to $\left.93 \%\right)$ had an odds ratio of $18.1(95 \% \mathrm{Cl} 8.2$ to 40.2$)$ for all outcomes within 48 hours when compared with the baseline group ( $\mathrm{SpO}_{2} 98 \%$ to $\left.100 \%\right)$.

Conclusion: Assessing $\mathrm{SpO}_{2}$ aids in the assessment of maternal risk in women admitted to hospital with preeclampsia. An $\mathrm{SpO}_{2}$ value of $\leq 93 \%$ confers particular risk. The symptom complex of chest pain and/or dyspnea adds to the association.

Key Words: Preeclampsia, pregnancy, oximetry

Competing Interests: None declared.

Received on September 13, 2010

Accepted on February 24, 2011

\section{Résumé}

Objectif : Nous avons cherché à déterminer le rôle de l'évaluation respiratoire en fonction des symptômes cardiorespiratoires et/ou celui de la détermination de la saturation en oxygène par oxymétrie pulsée $\left(\mathrm{SaO}_{2}\right)$ dans la prédiction des issues maternelles indésirables chez les femmes hospitalisées en raison d'une prééclampsie.

Méthodes : Ces données sont issues de l'étude de cohorte multicentrique prospective internationale PIERS (Pre-eclampsia Integrated Estimate of RiSk), laquelle a évalué les facteurs prédictifs des issues indésirables chez les femmes admises dans des unités périnatales tertiaires en raison d'une prééclampsie. Des analyses univariées et multivariées des symptômes cardiorespiratoires et de l'oxymétrie pulsée ont été menées pour en évaluer la capacité de prédire une issue maternelle indésirable combinée, élaborée par consensus Delphi international.

Résultats : $\mathrm{La} \mathrm{SaO}_{2}$ a permis de prédire avec succès les issues maternelles indésirables; la surface sous la courbe de la fonction d'efficacité de l'observateur-opérateur (AUC ROC) était de $0,71$ (IC à $95 \%, 0,65-0,77)$. Le fait de combiner les symptômes de la douleur thoracique et/ou de la dyspnée à l'oxymétrie pulsée a entraîné l'amélioration de cette capacité de prédiction (AUC ROC, $0,73$; IC à $95 \%, 0,67-0,78)$. Lorsque la $\mathrm{SaO}_{2}$ a été stratifiée en groupes de risque en fonction de points d'inflexion sur la courbe ROC, le groupe exposé au risque le plus élevé $\left(\mathrm{SaO}_{2} 90 \%\right.$ - $\left.93 \%\right)$ présentait un rapport de cotes de 18,1 (IC à $95 \%, 8,2-40,2$ ) pour toutes les issues dans un délai de 48 heures, par comparaison avec le groupe de base $\left(\mathrm{SaO}_{2} 98 \%-100 \%\right)$.

Conclusion : L'évaluation de la $\mathrm{SaO}_{2}$ contribue à l'évaluation du risque maternel chez les femmes hospitalisées en raison d'une prééclampsie. Une valeur de $\mathrm{SaO}_{2} \leq 93 \%$ confère un risque particulier. Le complexe de symptômes de la douleur thoracique et/ou de la dyspnée contribue à l'association. 


\section{INTRODUCTION}

Dreeclampsia is a multi-organ syndrome that may be characterized by multiple symptoms, signs, and laboratory assessments. It is generally defined as the presence of hypertension and proteinuria but can also involve hyperuricemia, hemolysis, liver perturbations, thrombocytopenia, and eclampsia. Preeclampsia remains the second leading global cause of maternal mortality. ${ }^{1}$

Current classifications of preeclampsia do not reliably predict adverse maternal or perinatal outcomes. The management of "severe" preeclampsia, as currently defined, may lead to inappropriate premature delivery as opposed to expectant management. ${ }^{2,3}$

Measurement of oxygen saturation by pulse oximetry is widely used clinically. There have been numerous studies with conflicting findings on the predictive value of $\mathrm{SpO}_{2}$ in adult and pediatric populations. ${ }^{4-9}$ While there are limited data related to a normal range in pregnancy against which to measure physiological perturbations, a suggested normal value for $\mathrm{SpO}_{2}$ in pregnancy is $\geq 97 \% .{ }^{10}$ The ability of maternal $\mathrm{SpO}_{2}$ to predict adverse maternal outcomes has been poorly studied, and in the few studies of the subject the definitions of oxygen desaturation events are inconsistent. Although most would agree that an $\mathrm{SpO}_{2}$ $<90 \%$ constitutes an abnormal value (or hypoxemia), some studies of pregnant women have used much higher values (up to $\mathrm{SpO}_{2}<95 \%$ ) to classify desaturations. ${ }^{11-14}$

In this study, we aimed to evaluate the predictive value of $\mathrm{SpO}_{2}$ in pregnant women admitted to hospital with preeclampsia and to establish risk levels that are more clinically informative than the simple and traditional classifications of "normal" or "hypoxic." A secondary aim was to determine whether or not the symptom complex of chest pain and/or dyspnea improves the discriminative power of $\mathrm{SpO}_{2}$ in assessing women admitted to hospital with preeclampsia.

\section{ABBREVIATIONS}

AUC area under the curve

BP blood pressure

CQI continuous quality improvement

HELLP hemolysis, elevated liver enzymes, low platelet count

PIERS Pre-eclampsia Integrated Estimate of RiSk

ROC receiver-operator characteristic

$\mathrm{SpO}_{2}$ oxygen saturation by pulse oximetry

\section{MATERIALS AND METHODS}

For this study we used data from the PIERS database. ${ }^{15}$ PIERS is an ongoing prospective study of women with preeclampsia admitted to obstetric centres that have a general policy of expectant management of preeclampsia remote from term. Data were collected on women admitted from September 2003 until January 2010. The centres (and level of neonatal intensive care) were British Columbia's Women's Hospital (level 3) and St Paul's Hospital (level 1), Vancouver, BC; Surrey Memorial Hospital (level 2), Surrey, BC; Kingston General Hospital (level 3), Kingston, ON; the Ottawa Hospital's General (level 3) and Civic (level 2) Campuses, Ottawa, ON; Centre Hospitalier Universitaire de Sherbrooke (level 3), Sherbrooke, QC; Christchurch Women's Hospital (level 3), Christchurch, New Zealand; King Edward Memorial Hospital for Women (level 3), Subiaco, Western Australia; Nottingham City Hospital (level 3), Nottingham, United Kingdom and St James's University Hospital (level 3), Leeds, United Kingdom. Until September 2007, women in four sites were required to give informed consent to be enrolled in PIERS; thereafter, in all but one of the sites enrolled, PIERS was conducted as a continuous quality improvement project. Research Ethics Board approval was obtained at all sites.

The CQI project entailed the introduction of predetermined guidelines for the initial assessment and ongoing surveillance of women admitted to hospital with either suspected or confirmed preeclampsia. The details of these guidelines have been previously published. ${ }^{16,17}$ Specifically, the guidelines recommended that oxygen assessment by pulse oximetry be performed once daily on the day of admission, on the day after admission, every subsequent Monday and Thursday, and on the day of delivery. It should be noted that these guidelines represented the minimum surveillance required, and repetition of tests in excess of the guidelines was at the discretion of the clinician.

Women hospitalized with gestational hypertension were evaluated for their eligibility for PIERS by a research assistant not involved in patient care. Inclusion criteria were (1) blood pressure $\geq 140 / 90 \mathrm{mmHg}$ (measured on two occasions at least four hours apart, after 20 weeks'gestation) and either proteinuria (of $\geq 2+$ by dipstick, $\geq 0.3 \mathrm{~g} /$ day by 24-hour urine collection, or $>30 \mathrm{mg} / \mathrm{mmol}$ by spot urinary protein:creatinine ratio), or hyperuricemia (greater than the local upper limit of normal for non-pregnant individuals); (2) HELLP syndrome even in the absence of hypertension or proteinuria; or (3) superimposed preeclampsia, defined as pre-existing hypertension with accelerated hypertension (as diagnosed by the clinician or defined as a systolic $\mathrm{BP} \geq 170 \mathrm{mmHg}$ or diastolic $\mathrm{BP} \geq 120 \mathrm{mmHg}$ ), new 


\section{Table 1. Characteristics of women in the PIERS study}

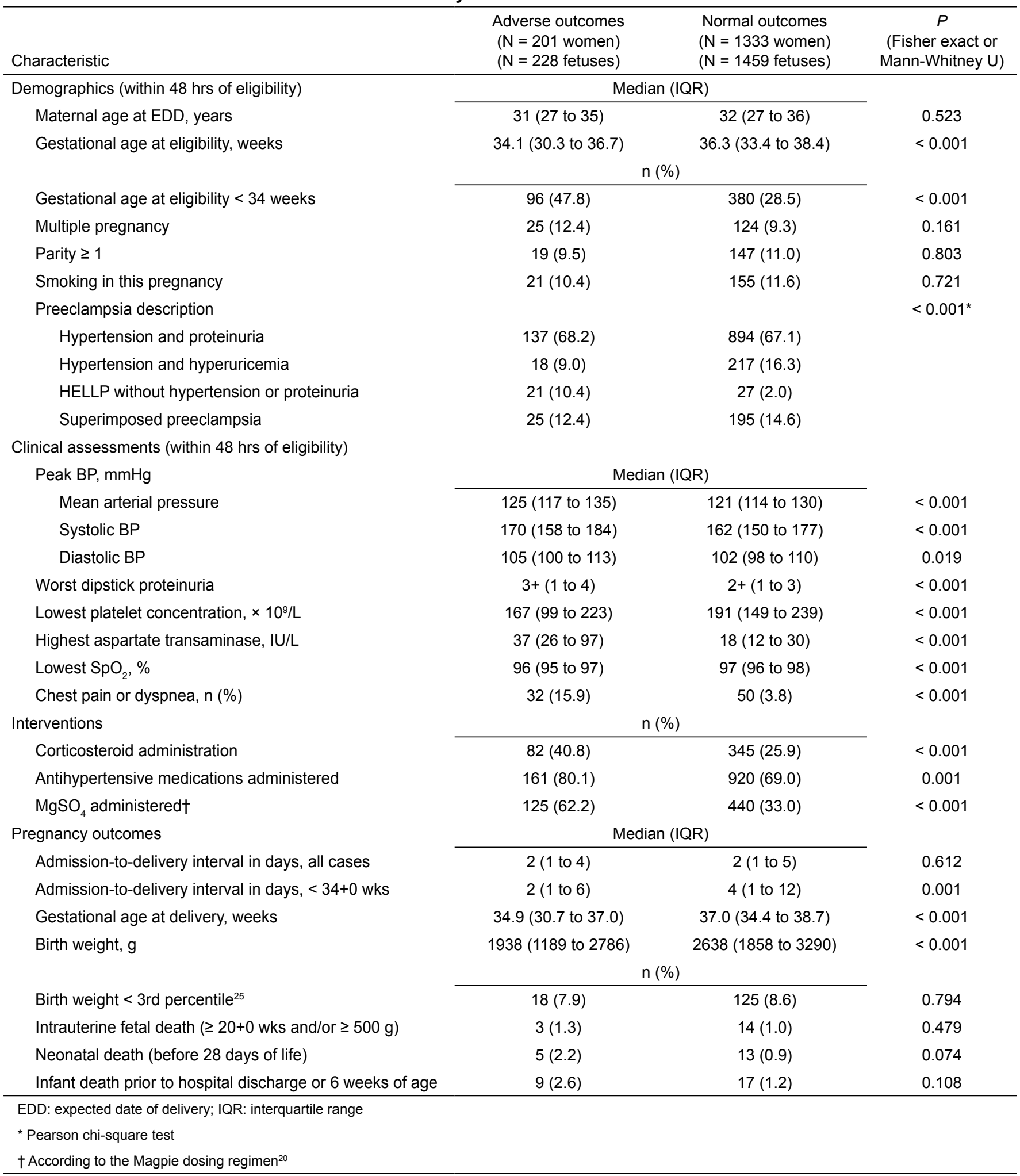




\begin{tabular}{|c|c|c|c|}
\hline One or more of maternal morbidity or mortality: & $\begin{array}{c}\text { Within } 48 \text { hours } \\
\mathrm{n}(\%)\end{array}$ & $\begin{array}{l}\text { Within } 7 \text { days } \\
\quad \mathrm{n}(\%)\end{array}$ & $\begin{array}{l}\text { At any time } \\
\mathrm{n}(\%)\end{array}$ \\
\hline Total adverse outcomes & $94(6.1)$ & $168(11.0)$ & $201(13.1)$ \\
\hline Total non-respiratory adverse outcomes & $67(4.4)$ & $114(7.4)$ & $137(8.9)$ \\
\hline Maternal death & 0 & 0 & 0 \\
\hline \multicolumn{4}{|l|}{ Central nervous system } \\
\hline Eclampsia $(\geq 1)$ & 5 & 8 & 9 \\
\hline Glasgow coma score $<13$ & 1 & 1 & 2 \\
\hline Stroke or reversible ischemic neurological deficit & 0 & 0 & 1 \\
\hline Transient ischemic attack & 0 & 1 & 1 \\
\hline Cortical blindness or retinal detachment & 0 & 0 & 0 \\
\hline Posterior reversible encephalopathy & 0 & 0 & 0 \\
\hline \multicolumn{4}{|l|}{ Cardiorespiratory } \\
\hline Positive inotropic support & 0 & 0 & 1 \\
\hline Infusion of a 3rd parenteral antihypertensive & 0 & 1 & 2 \\
\hline Myocardial ischemia/infarction & 1 & 1 & 1 \\
\hline $\mathrm{SpO}_{2}<90 \%$ & 11 & 23 & 28 \\
\hline$\geq 50 \% \mathrm{FiO}_{2}$ for $>1 \mathrm{hr}$ & 12 & 16 & 21 \\
\hline Intubation & 1 & 4 & 6 \\
\hline Pulmonary edema & 22 & 42 & 47 \\
\hline \multicolumn{4}{|l|}{ Hematological } \\
\hline Transfusion of any blood product & 27 & 57 & 69 \\
\hline Platelet concentration $<50 \times 10^{9} / \mathrm{L}$ with no transfusion & 20 & 29 & 29 \\
\hline \multicolumn{4}{|l|}{ Hepatic } \\
\hline Dysfunction & 8 & 10 & 10 \\
\hline Hematoma/rupture & 0 & 0 & 0 \\
\hline \multicolumn{4}{|l|}{ Renal } \\
\hline $\begin{array}{l}\text { Acute renal insufficiency (serum creatinine }>150 \mu \mathrm{mol} / \mathrm{L} \text {, } \\
\text { no renal disease) }\end{array}$ & 3 & 4 & 5 \\
\hline $\begin{array}{l}\text { Acute renal failure (serum creatinine }>200 \mu \mathrm{mol} / \mathrm{L} \\
\text { with renal disease) }\end{array}$ & 3 & 3 & 3 \\
\hline Dialysis & 0 & 0 & 1 \\
\hline \multicolumn{4}{|l|}{ Placental outcomes } \\
\hline Placental abruption & 12 & 19 & 26 \\
\hline \multicolumn{4}{|l|}{ Other adverse events } \\
\hline Ascites & 1 & 2 & 2 \\
\hline Bell's palsy & 0 & 0 & 0 \\
\hline
\end{tabular}

proteinuria, or new hyperuricemia. Women were excluded if they were admitted in active labour or if they achieved any component of the combined adverse maternal outcome prior to collection of predictors. This inclusive definition was chosen to reflect the variable and multisystemic nature of preeclampsia seen in clinical practice.

The PIERS database contains extensive data on each patient, including lowest daily $\mathrm{SpO}_{2}$ as documented in the patient's chart and daily occurrence of the combined cardiorespiratory symptoms of chest pain and/or dyspnea.

The PIERS combined adverse maternal outcome was developed by iterative Delphi consensus (members of the consensus panel are listed at the PIERS website ${ }^{18}$ ), and includes maternal death and hepatic, central nervous system, renal, cardiorespiratory, and hematological morbidities. 


\begin{tabular}{|c|c|c|c|c|c|}
\hline Variable & Outcome type & Time & OR $(95 \% \mathrm{Cl})$ & $P$ & AUC ROC $(95 \% \mathrm{Cl})$ \\
\hline \multirow[t]{6}{*}{ Oxygen saturation } & \multirow[t]{3}{*}{ All adverse outcomes } & $48 \mathrm{hrs}$ & $0.67(0.61$ to 0.74$)$ & $<0.001$ & 0.71 (0.65 to 0.77$)$ \\
\hline & & 7 days & $0.78(0.72$ to 0.84$)$ & $<0.001$ & 0.61 (0.56 to 0.66$)$ \\
\hline & & Any time & $0.82(0.76$ to 0.89$)$ & $<0.001$ & 0.58 (0.53 to 0.62$)$ \\
\hline & \multirow{3}{*}{$\begin{array}{l}\text { Non-respiratory } \\
\text { adverse outcomes }\end{array}$} & $48 \mathrm{hrs}$ & 0.77 (0.68 to 0.86$)$ & $<0.001$ & $0.64(0.57$ to 0.71$)$ \\
\hline & & 7 days & 0.87 (0.79 to 0.96$)$ & 0.004 & 0.57 (0.51 to 0.62$)$ \\
\hline & & Any time & $0.90(0.82$ to 0.99$)$ & 0.025 & 0.54 (0.49 to 0.59$)$ \\
\hline \multirow[t]{6}{*}{ Chest pain and/or dyspnea } & \multirow[t]{3}{*}{ All adverse outcomes } & $48 \mathrm{hrs}$ & 6.01 (3.45 to 10.46$)$ & $<0.001$ & $0.59(0.52$ to 0.65$)$ \\
\hline & & 7 days & 4.24 (2.61 to 7.04$)$ & $<0.001$ & $0.56(0.51$ to 0.61$)$ \\
\hline & & Any time & 4.86 (3.03 to 7.79$)$ & $<0.001$ & $0.56(0.52$ to 0.61$)$ \\
\hline & \multirow{3}{*}{$\begin{array}{l}\text { Non-respiratory } \\
\text { adverse outcomes }\end{array}$} & $48 \mathrm{hrs}$ & 2.17 (0.96 to 4.90$)$ & 0.064 & $0.53(0.45$ to 0.60$)$ \\
\hline & & 7 days & 1.37 (0.64 to 2.93$)$ & 0.411 & 0.51 (0.45 to 0.57$)$ \\
\hline & & Any time & $1.82(0.96$ to 3.45$)$ & 0.066 & $0.52(0.47$ to 0.57$)$ \\
\hline
\end{tabular}

The potential for lead-time bias was addressed by standardizing eligibility only from hospitalization with preeclampsia, and not necessarily from disease onset. Incompetence bias (missing values and misclassification) was reduced by abstractor training, development and validation of the Microsoft Access database, feasibility and development studies using that database, and random reabstraction of charts. Misclassification errors were further minimized by database surveillance and 5\% reabstraction. The study was pragmatic, and test reproducibility was not examined, consistent with clinical care; we relied on inhouse training and review for ensuring test reproducibility. Customized case report forms and a Microsoft Access database were created for data entry and used at all participating sites. Data were collected from the women's medical records.

The value for oxygen saturation used in this study was the lowest $\mathrm{SpO}_{2}$ value recorded in each patient's medical record within 48 hours after fulfilling the eligibility criteria or before the occurrence of an adverse outcome, whichever occurred first. The dependent variables we examined were all dichotomous. We investigated combined adverse maternal outcome (defined above) within 48 hours, within seven days, and at any time. A second adverse outcome variable (non-respiratory adverse outcomes) was developed that excluded the adverse respiratory outcomes (pulmonary edema, $\mathrm{SpO}_{2}<90 \%$, intubation, and requirement of $\geq 50 \%$ fraction of inspired oxygen for more than one hour). For this second outcome variable, women with only respiratory adverse outcomes were coded as having a normal outcome, whereas women who experienced at least one non-respiratory adverse outcome were coded as having had an adverse outcome.
The key independent variable investigated was $\mathrm{SpO}_{2}$. This was both analyzed as a continuous variable and stratified into risk groups using inflection points on the ROC curve (baseline $[98 \%$ to $100 \%]$, low risk [96\% to $97 \%$, medium risk [ $94 \%$ to $95 \%$, and high risk [90\% to $93 \%]$ ). The dichotomous independent variable of cardiorespiratory symptoms (chest pain and/or dyspnea) was also investigated.

Each of the independent variables $\left(\mathrm{SpO}_{2}\right.$ and cardiorespiratory symptoms) was analyzed using a univariate logistic regression to examine any potential relationship with the combined adverse maternal outcome and non-respiratory adverse outcome within 48 hours, within seven days, and at any time. These independent variables were then combined using a multivariate logistic regression analysis to determine if combining them would enhance the predictive power of the model. Area under the curve of the receiver-operator characteristic was calculated to show the relationship between true-positive and false-positive ratios. A minimum AUC ROC of $>0.7$ is needed to indicate an adequately discriminative test. A perfectly discriminative test would have an AUC ROC of 1.0 and a completely non-discriminative test would have an AUC ROC of 0.5 . Odds ratios with $95 \%$ confidence intervals were calculated using the stratified oxygen saturation baseline and low, medium, and high risk groups. Each risk group was compared with the baseline group; therefore, the baseline group always had a relative risk of 1.0. Odds ratios were calculated using a multivariate logistic regression with dummy variables for each risk group. All statistical analyses were performed using SPSS 17.0 (IBM, Somers NY). All figures were produced using GraphPad Prism 4 (GraphPad, San Diego, CA). 


\begin{tabular}{|c|c|c|c|}
\hline Predictor & $\beta$-coefficient $(95 \% \mathrm{Cl})$ & $P$ & OR $(95 \% \mathrm{Cl})$ \\
\hline Cardiorespiratory symptoms & $1.404(0.802$ to 2.006$)$ & $<0.001$ & 4.07 (2.23 to 7.43$)$ \\
\hline $\mathrm{SpO}_{2}$ & $-0.362(-0.464$ to -0.260$)$ & $<0.001$ & $0.70(0.63$ to 0.77$)$ \\
\hline Constant & 31.861 (22.222 to 41.500$)$ & $<0.001$ & Not applicable \\
\hline
\end{tabular}

\section{RESULTS}

Of the 2023 women entered in the PIERS database between September 1, 2003, and January 31, 2010, 1534 women were eligible for this study, having had an $\mathrm{SpO}_{2}$ recorded within 48 hours of eligibility or prior to the occurrence of an adverse outcome. The remaining 489 women were excluded because they lacked an $\mathrm{SpO}_{2}$ value for the first 48 hours after eligibility or before the occurrence of an adverse outcome. The demographics of the study cohort, comparing those with any aspect of the combined adverse maternal outcome at any time ( $\mathrm{n}=201 ; 13.1 \%)$ with those with normal outcomes, are shown in Table 1 . Women who experienced adverse outcomes tended to have a lower gestational age, were more likely to have HELLP syndrome, and were less likely to have preeclampsia diagnosed on the basis of hypertension and hyperuricemia. Women with adverse outcomes were sicker overall; they were more hypertensive and more proteinuric, had higher liver enzyme levels, lower platelet counts, and lower $\mathrm{SpO}_{2}$ levels, and were more likely to have experienced cardiorespiratory symptoms. Women with adverse outcomes were also more likely to have had therapeutic interventions, including corticosteroids, antihypertensives, and magnesium sulphate. These women also delivered babies with lower birth weights at earlier gestational ages, but there was no statistically significant increase in perinatal or infant mortality.

The outcomes experienced by women in this study are shown in Table 2. A total of 201 women (13.1\%) experienced at least one component of the combined adverse maternal outcome at some time. The most common outcomes were pulmonary edema $(47,3.1 \%)$ and blood transfusion $(69,4.5 \%)$. Of the 201 women, 137 (8.9\%) experienced one or more non-respiratory components of the adverse maternal outcome.

Univariate logistic regression coefficients were significant for both $\mathrm{SpO}_{2}$ and cardiorespiratory symptoms for prediction of "all outcomes" at any time $(P<0.001)$ (Table 3). The AUC ROC for $\mathrm{SpO}_{2}$ alone was 0.71 ( $95 \%$ CI 0.65 to 0.77 ) for predicting adverse maternal outcomes within 48 hours (Table 3). The multivariate regression analysis for $\mathrm{SpO}_{2}$ and cardiorespiratory symptoms is presented in Table 4 , and the final predictive equation for all outcomes within 48 hours is

$$
\begin{aligned}
\operatorname{logit}(\mathrm{p})= & \ln \frac{\mathrm{p}}{1-\mathrm{p}}=31.86-0.362 \times \text { oxygen saturation }+ \\
& 1.404 \times \text { cardiorespiratory symptoms }
\end{aligned}
$$

The AUC ROC for this model is 0.73 (95\% CI 0.67 to 0.78) (Figure 1). The predicted probabilities of adverse outcome based on this model are shown in Figure 2. It is clear that the addition of cardiorespiratory symptoms adds to the discriminative power of the model.

A sensitivity analysis was performed to assess the strength of $\mathrm{SpO}_{2}$ and cardiorespiratory symptoms in predicting nonrespiratory adverse outcomes. $\mathrm{SpO}_{2}$ performed less well in predicting non-respiratory adverse outcomes only (regression coefficient $-0.267, P<0.001$; AUC ROC 0.64 [95\% CI 0.57 to 0.71$]$ ) (Table 3). Cardiorespiratory symptoms were not predictive of non-respiratory adverse outcomes by univariate logistic regression (regression coefficient $0.74, P=0.08$ ) or when combined with oxygen saturation (regression coefficient $0.36, P=0.41$ ) (data not shown).

Inflection points from the ROC curve of $\mathrm{SpO}_{2}$ predicting any adverse outcomes within 48 hours were used to stratify the risk of $\mathrm{SpO}_{2}$ from $90 \%$ to $100 \%$, inclusive. Four inflection points were identified representing oxygen saturations of $93.5 \%, 95.5 \%, 97.5 \%$, and $98.5 \%$ (Figure 3). Therefore, $98 \%$ to $100 \%$ was defined as baseline, $96 \%$ to $97 \%$ as low risk, $94 \%$ to $95 \%$ as medium risk, and $90 \%$ to $93 \%$ as high risk. The odds of any adverse outcome within 48 hours in the high-risk group was 18-fold higher than in the baseline group $(P<0$. 001) (Table 5). Additionally, the high-risk group had higher odds of non-respiratory adverse outcomes within 48 hours than the baseline group $(P<0.001)$ (Table 5). At 48 hours, the odds of "all adverse outcomes" were significantly higher in all risk groups (low, medium, high) than in the baseline group. As the interval between eligibility and adverse outcome increased, the OR decreased and became less significant. However, the highrisk group had significantly higher odds ratios for both all adverse outcomes $(P<0.001)$ and non-respiratory adverse outcomes $(P<0.01$ to $P<0.001)$ across all time points. 


\begin{tabular}{|c|c|c|}
\hline Risk group $\left(\mathrm{SpO}_{2}\right)$ & All adverse outcomes & Non-respiratory adverse outcomes \\
\hline \multicolumn{3}{|l|}{ Adverse outcome within $48 \mathrm{hrs}$} \\
\hline High risk (90 to $93 \%$ ) & $18.10(8.15 \text { to } 40.18)^{\star \star *}$ & $6.99(2.86 \text { to } 17.10)^{\star \star *}$ \\
\hline Medium risk (94 to $95 \%$ ) & $4.82(2.27 \text { to } 10.65)^{\star \star *}$ & $3.30(1.46 \text { to } 7.46)^{* *}$ \\
\hline Low risk (96 to $97 \%$ ) & $2.54(1.20 \text { to } 5.35)^{*}$ & 2.14 (1.00 to 4.57$)$ \\
\hline \multicolumn{3}{|l|}{ Adverse outcome within 7 days } \\
\hline High risk (90 to $93 \%$ ) & $5.89(3.41 \text { to } 10.15)^{\star \star \star}$ & $3.15(1.59 \text { to } 6.22)^{\star *}$ \\
\hline Medium risk (94 to $95 \%$ ) & $1.71(1.05 \text { to } 2.80)^{\star}$ & $1.56(0.88$ to 2.80$)$ \\
\hline Low risk (96 to $97 \%$ ) & 1.27 (0.83 to 1.96$)$ & 1.37 (0.84 to 2.25$)$ \\
\hline \multicolumn{3}{|l|}{ Adverse outcome at any time } \\
\hline High risk (90 to $93 \%$ ) & $4.46(2.67 \text { to } 7.43)^{\star * \star}$ & $2.55(1.36 \text { to } 4.77)^{\star *}$ \\
\hline Medium risk (94 to $95 \%$ ) & $1.22(0.78$ to 1.93$)$ & $1.14(0.67$ to 1.95$)$ \\
\hline Low risk (96 to $97 \%$ ) & $1.13(0.77$ to 1.64$)$ & $1.17(0.76$ to 1.80$)$ \\
\hline \multicolumn{3}{|c|}{$\begin{array}{l}\text { All odds ratios are compared with a baseline } \mathrm{SpO}_{2} \text { of } 98 \% \text { to } 100 \% \text { using multivariate logistic regression; } \\
P \text { values were calculated using Wald's chi-square. } \\
{ }^{*} P<0.05 ;{ }^{* *} P<0.01 ;{ }^{* * *} P<0.001 \text { ). }\end{array}$} \\
\hline
\end{tabular}

Chi-square for trend tests were significant across all time points and for both adverse outcome variables (data not shown).

It should be noted that maternal $\mathrm{SpO}_{2}$ was not predictive of perinatal outcomes (data not shown).

\section{DISCUSSION}

Our findings suggest that maternal $\mathrm{SpO}_{2}$ usefully predicts adverse maternal outcomes in women admitted to hospital with preeclampsia. $\mathrm{SpO}_{2}$ was best at prediction of any adverse maternal outcome within 48 hours, especially when combined with cardiorespiratory symptoms (AUC ROC 0.73). The variables used in analysis were collected within 48 hours of eligibility (and before outcome occurrence), so it is logical to conclude that $\mathrm{SpO}_{2}$ predicts adverse outcomes within the same time. However, $\mathrm{SpO}_{2}$ within the first 48 hours remained predictive of adverse outcomes within seven days and at any time.

The study also revealed that $\mathrm{SpO}_{2}$ of $90 \%$ to $93 \%$ was independently associated with an 18-fold increase in the odds of an adverse outcome within 48 hours compared with a normal $\mathrm{SpO}_{2}(98 \%$ to $100 \%)$.

In preeclampsia, hypoxemia may result from a number of mechanisms. Pulmonary vasospasm and inflammation may result in decreased pulmonary vascular perfusion and a ventilation-perfusion mismatch. The combined effects of hypoalbuminemia, which leads to decreased oncotic pressure, and endothelial dysfunction, which increases permeability of the pulmonary vasculature, may result in non-cardiogenic pulmonary edema and impaired pulmonary diffusion capacity. A less common mechanism is hypoventilation resulting from central nervous system complications (and obtundation) or magnesium toxicity. ${ }^{19}$

Because we expected $\mathrm{SpO}_{2}$ to be predictive of respiratory adverse outcomes such as pulmonary edema, we additionally examined the generalizability of the predictive power of $\mathrm{SpO}_{2}$ by performing a sensitivity analysis examining its relationship with non-respiratory adverse outcomes. The

Figure 1. Area under the curve of the receiveroperator characteristic for the ability of $\mathrm{SpO}_{2}$ and cardiorespiratory symptoms combined to predict all outcomes within 48 hours

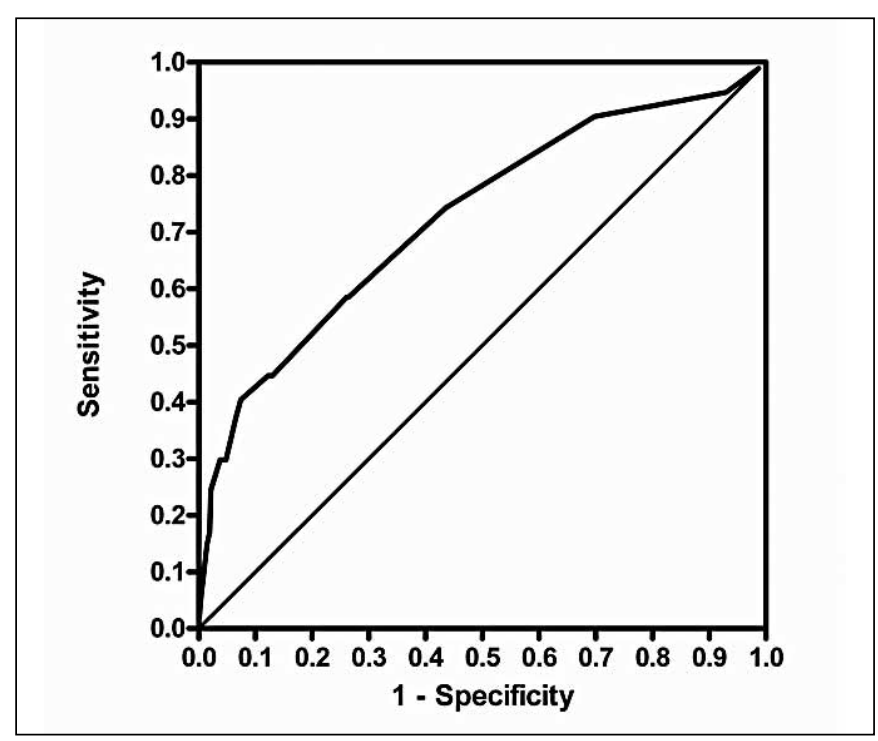


Figure 2. (A) Predicted probability of outcome by multivariate logistic regression showing the difference in probability of outcome with or without cardiorespiratory symptoms. (B) Predicted probability of outcome by univariate logistic regression comparing probability for all outcomes and for non-respiratory outcomes

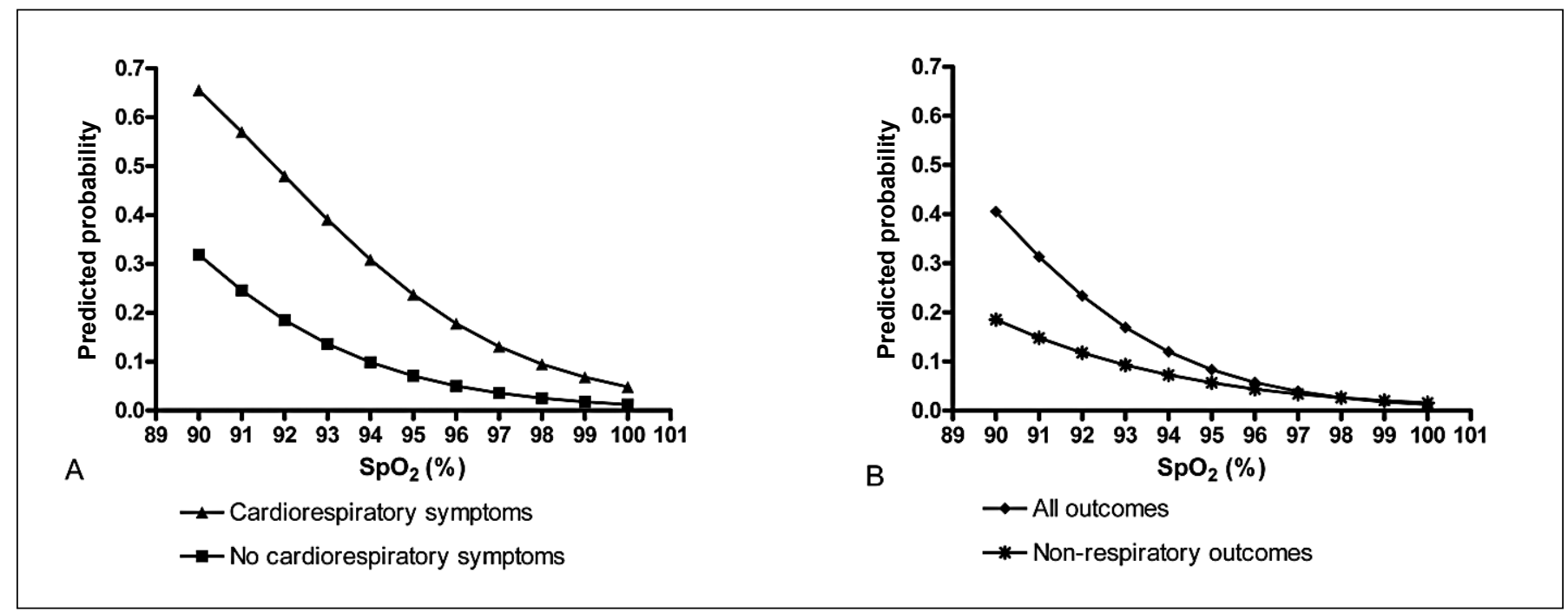

AUC ROC for $\mathrm{SpO}_{2}$ was only 0.64 for prediction of nonrespiratory adverse outcomes within 48 hours. However, stratified pulse oximetry was significantly associated with risk of non-respiratory adverse outcomes within 48 hours (OR 6.99 for $\mathrm{SpO}_{2} 90 \%$ to $93 \%$ compared with $\mathrm{SpO}_{2}$ $98 \%$ to $100 \%$ ). Increased odds of adverse outcome in the high-risk group ( $\mathrm{SpO}_{2} 90$ to 93\%) were statistically significant for all time periods (48 hours, 7 days, and any time) and for all adverse outcome groups (all outcomes and non-respiratory outcomes).

Figure 3. Inflection points on the area under the receiver-operator characteristic curve of $\mathrm{SpO}_{2}$ alone predicting all outcomes within $\mathbf{4 8}$ hours. Arrowheads $(4)$ indicate the inflection points identified.

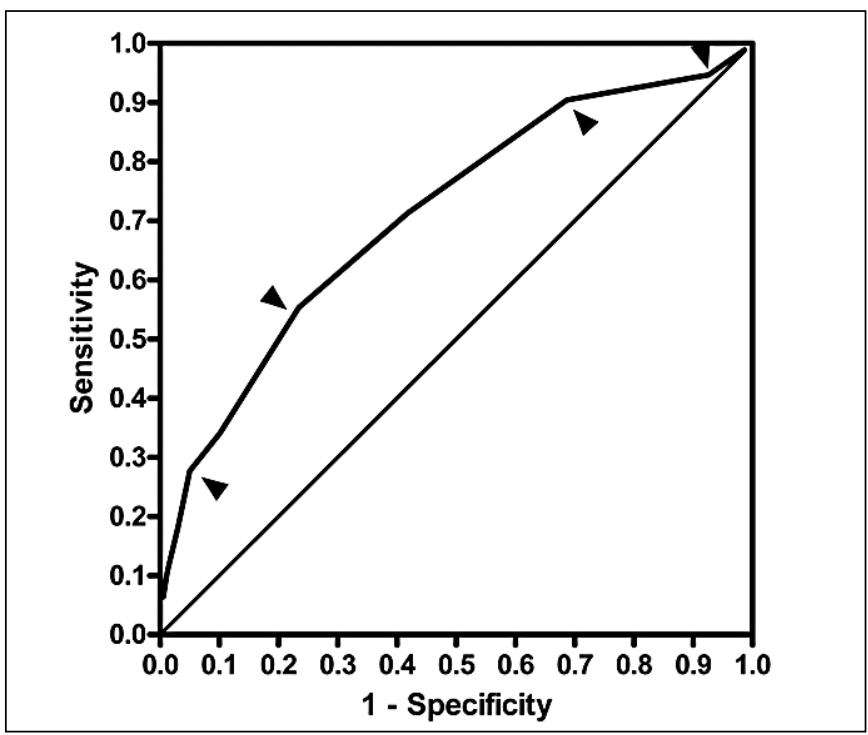

To our knowledge, this is the first study of maternal pulse oximetry as a predictor of adverse maternal outcome in women with preeclampsia. Our multicentre prospective study of women admitted with preeclampsia features a large international sample $(\mathrm{n}=1534)$.

We investigated whether or not treatment with magnesium sulphate may confound the findings of this study. Magnesium sulphate was administered according to the Magpie regimen ${ }^{20}$ to $62.2 \%$ of women who developed an adverse outcome and to $33.0 \%$ of those who did not. However, rather than magnesium sulphate being on the causative pathway to outcome, we believe that the sicker women who therefore went on to develop an adverse outcome were also the women who were more likely to receive magnesium sulphate. In order to prevent overreporting of adverse outcomes resulting from the side effects of magnesium sulphate use, this study used a Glasgow Coma Scale score of $<13$ (rather than $<15$ ) as the criterion for adverse outcome to account for the drowsiness associated with magnesium sulphate use. In examining the relationship between preeclampsia, magnesium sulphate, and $\mathrm{SpO}_{2}$, Thorp et al. ${ }^{13}$ did not find a higher risk of oxygen desaturation in women with preeclampsia than in women receiving magnesium sulphate for other reasons; $\mathrm{SpO}_{2}<90 \%$ was used as the definition of oxygen desaturation. The major weakness of this study is that 489 women $(25 \%)$ in the PIERS database were excluded because they did not have $\mathrm{SpO}_{2}$ recorded within 48 hours of eligibility and before occurrence of an adverse outcome, yet 60 of these women (12.3\%) experienced one or more components of the combined adverse maternal 
outcome. This lack of compliance with the PIERS study protocol may be indicative of selection bias, with sicker women being selected for $\mathrm{SpO}_{2}$ monitoring, but the outcome incidence was not significantly different between groups; $12.3 \%$ of excluded women had an adverse outcome, compared with the $13.1 \%$ adverse outcome rate observed in the women under study $(P=0.688)$. Alternatively, it may reflect random deviation from the protocol and overall lower levels of monitoring in the early stages of the study; $26.5 \%$ of women were excluded from the development database, whereas only $20.3 \%$ were excluded from the validation database $(P<0.002)$.

A second limitation of the study is that we included women with hyperuricemic, non-proteinuric hypertension in our cohort. However, the inclusion of these women is consistent with the additional risks surrounding hyperuricemia ${ }^{21}$ and with our wider aim of developing a generalizable model.

The recording of only the lowest oxygen saturation within 48 hours represents a third weakness of this study. Possible false readings from the pulse oximeter were not addressed. However, such events would be expected to occur at random, and would not be associated with women more likely to develop an adverse outcome. Furthermore, differences in training in pulse oximetry use between care providers were not specifically addressed, as this was an observational rather than an interventional study.

An $\mathrm{SpO}_{2}$ level $<90 \%$ is considered to be abnormal or representative of hypoxemia. ${ }^{13,14}$ In the current study, and supported by our Delphi consensus group, $\mathrm{SpO}_{2}$ $<90 \%$ was a component of the combined adverse maternal outcome. As the PIERS study aims to predict outcomes, only the pulse oximetry readings before an adverse outcome were used and, therefore, there are no values for $\mathrm{SpO}_{2}<90 \%$ in the PIERS database. This may represent a limitation of our study in that we were unable to evaluate the role of pulse oximetry readings below $90 \%$ in predicting other adverse outcomes. However, there have been no standardized cut-off points for describing abnormal values in pregnant women. Previous studies have used $\mathrm{SpO}_{2}$ values of $<90 \%,<94 \%$, and/or $<95 \%$ as their cut-off points in the evaluation of $\mathrm{SpO}_{2}{ }^{11-13}$ The results presented show a clear trend of increasing risk for adverse outcome with decreasing $\mathrm{SpO}_{2}$; this trend probably continues below the current data range. It is evident that for pregnant women the use of only one cut-off point is probably an oversimplification, and $\mathrm{SpO}_{2}$ can be stratified into groups with variable degrees of risk. Also, the $\mathrm{SpO}_{2}$ value we used as the baseline or normal range for pregnant women $(\geq 98 \%)$ is higher than previously reported. ${ }^{22}$
The clinical syndrome of preeclampsia can have a very rapid onset, with seemingly healthy women deteriorating quickly. Preeclampsia is linked with serious maternal comorbidities, including pulmonary edema and acute respiratory distress syndrome. ${ }^{23-25}$ Both of these complications may result in decreased blood gas exchange across the alveoli, with consequent hypoxemia. While maternal blood gas testing is important for the diagnosis of hypoxemia, it is expensive, invasive, painful, and slow, whereas $\mathrm{SpO}_{2}$ is cheap, quick, and non-invasive. Respiratory rate, which is the other bedside method for evaluating possible respiratory distress, is poorly assessed and recorded. ${ }^{26}$ Therefore, $\mathrm{SpO}_{2}$ is a strong candidate for use as a screening tool. ${ }^{9}$

Our data were limited to inpatient women who had pregnancies complicated by preeclampsia, albeit broadly and pragmatically defined. It will be important to assess the role of pulse oximetry in outpatient women with preeclampsia, as well as in women whose pregnancies have been complicated by the other hypertensive disorders of pregnancy (i.e., preexisting and non-proteinuric gestational hypertension). ${ }^{15}$ Further research is also indicated to test whether a change in $\mathrm{SpO}_{2}$, or in the rate of change, might usefully predict adverse maternal outcome in women with preeclampsia. The present study was limited to recording only the lowest daily $\mathrm{SpO}_{2}$.

How measurements of $\mathrm{SpO}_{2}$ correlate with adverse outcomes in a multivariable regression model, to further clarify their role in the care of women suffering from a complex and highly variable clinical syndrome, has been assessed in the development and validation of the full PIERS model..$^{15}$

\section{CONCLUSION}

We have determined that assessing $\mathrm{SpO}_{2}$ by pulse oximetry aids in the assessment of maternal risk in women admitted to hospital with preeclampsia. An $\mathrm{SpO}_{2}$ value $\leq 93 \%$ confers particular risk. The symptom complex of chest pain and/or dyspnea adds some strength to the association.

\section{ACKNOWLEDGEMENTS}

Funding for the PIERS study is provided by Canadian Institutes for Health Research, UNDP/UNFPA/WHO/ World Bank Special Programme of Research, Development \& Research Training in Human Reproduction, Michael Smith Foundation for Health Research, and the Child and Family Research Institute.

The other members of the PIERS Study Group are: in Australia: Barry N. Walters; in Canada, J. Mark Ansermino, Samantha Benton, Anne-Marie Côté, Geoff Cundiff, 
Andrée Gruslin, Dany Hugo, K.S. Joseph, Sayrin Lalji, Shoo K. Lee, Jing Li, Paula Lott, Jennifer Menzies, Jean-Marie Moutquin, Annie B. Ouellet, James A. Russell, Dorothy Shaw (for FIGO), Graeme N. Smith, D. Keith Still, George Tawagi, and Brenda Wagner; in Fiji: Swati Mahajan and Amanda Noovao; in New Zealand: Phillipa M. Kyle and M. Peter Moore; in South Africa: David Hall and D. Wilhelm Steyn; in Uganda: Christine Biryabarema, Florence Mirembe, and Annettee Nakimuli; in the United Kingdom: Fiona Broughton Pipkin, Pamela Loughna, and James J. Walker; in the United States: William Grobman and Eleni Tsigas (for the Preeclampsia Foundation); and at the WHO: Mario Merialdi and Mariana Widmer.

\section{REFERENCES}

1. World Health Organisation, UNFPA, UNDP, The World Bank, UNICEF. Maternal mortality in 2005: estimates developed by WHO, UNICEF, UNFPA, and The World Bank. Geneva: WHO; 2007.

2. Menzies J, Magee LA, Macnab YC, Ansermino JM, Li J, Douglas MJ, et al. Current CHS and NHBPEP criteria for severe preeclampsia do not uniformly predict adverse maternal or perinatal outcomes. Hypertens Pregnancy 2007;26:447-62.

3. von Dadelszen P, Menzies JM, Payne B, Magee LA. Predicting adverse outcomes in women with severe pre-eclampsia. Semin Perinatol 2009 Jun;33:152-7.

4. De Felice C, Leoni L, Tommasini E, Tonni G, Toti P, Del Vecchio A, et al. Maternal pulse oximetry perfusion index as a predictor of early adverse respiratory neonatal outcome after elective cesarean delivery. Pediatr Crit Care Med 2008;9:203-8.

5. East CE, Chan FY, Colditz PB, Begg LM. Fetal pulse oximetry for fetal assessment in labour. Cochrane Database Syst Rev 2007;(2):CD004075.

6. Nordenholz K, Ryan J, Atwood B, Heard K. Pulmonary embolism risk stratification: pulse oximetry and pulmonary embolism severity index. J Emerg Med 2011;40:95-102.

7. Pedersen T, Moller AM, Hovhannisyan K. Pulse oximetry for perioperative monitoring. Cochrane Database Syst Rev 2009;(4):CD002013.

8. Shoemaker WC, Wo CC, Lu K, Chien LC, Bayard DS, Belzberg H, et al. Outcome prediction by a mathematical model based on noninvasive hemodynamic monitoring. J Trauma 2006;60:82-90.

9. Witting MD, Lueck CH. The ability of pulse oximetry to screen for hypoxemia and hypercapnia in patients breathing room air. J Emerg Med 2001;20:341-8.

10. Van Hook JW, Harvey CJ, Anderson GD. Effect of pregnancy on maternal oxygen saturation values: use of reflectance pulse oximetry during pregnancy. South Med J 1996;89:1188-92.
11. Griffin RP, Reynolds F. Maternal hypoxaemia during labour and delivery: the influence of analgesia and effect on neonatal outcome. Anaesthesia 1995;50:151-6.

12. Porter JS, Bonello E, Reynolds F. The effect of epidural opioids on maternal oxygenation during labour and delivery. Anaesthesia 1996;51:899-903.

13. Thorp JA, Neimark M, Poskin M. Maternal oxygen desaturation with intravenous magnesium therapy. Obstet Gynecol 1997;89:963-6.

14. Valdez-Lowe C, Ghareeb SA, Artinian NT. Pulse oximetry in adults. Am J Nurs 2009;109:52-9.

15. von Dadelszen P, Payne B, Li J, Ansermino JM, Broughton Pipkin F, Cote AM, et al. Predicting adverse maternal outcomes in pre-eclampsia: the fullPIERS (Pre-eclampsia Integrated Estimate of RiSk) modeldevelopment and validation. Lancet 2011;377:219-27.

16. Magee LA, Helewa ME, Moutquin JM, von Dadelszen P, Cardew S, Cote AM, et al. Diagnosis, evaluation and management of the hypertensive disorders of pregnancy. SOGC Clinical Practice Guidelines, No. 206, March 2008. J Obstet Gynaecol Can 2008;30(3 Suppl 1):S1-S48.

17. Menzies J, Magee LA, Li J, Yin R, Lam E, Stuart H, et al. Instituting surveillance guidelines and adverse outcomes in preeclampsia: a single site study. Obstet Gynecol 2007;110:121-7.

18. Pre-eclampsia Integrated Estimate of RiSk (PIERS) [website]. University of British Columbia Child and Family Research Institute. Available at: http:// piers.cfri.ca. Accessed May 13, 2011.

19. West JB. Chapter 5. Ventilation-perfusion relationships. In: Respiratory physiology: the essentials. 8th ed. Philadelphia: Lippincott Williams \& Wilkins; 2008:55-74.

20. Duley L, Farrell B, Spark P, Roberts B, Watkins K, Bricker L, et al. Do women with pre-eclampsia, and their babies, benefit from magnesium sulphate? The Magpie Trial: a randomised placebo-controlled trial. Lancet 2002;359(9321):1877-90.

21. Roberts JM, Bodnar LM, Lain KY, Hubel CA, Markovic N, Ness RB, et al. Uric acid is as important as proteinuria in identifying fetal risk in women with gestational hypertension. Hypertension 2005;46:1263-9.

22. Richlin S, Cusick W, Sullivan C, Dildy G, Belfort M. Normative oxygen saturation values for pregnant women at sea level. Prim Care Update Ob Gyns 1998;5:154-5.

23. Lewis G. Saving mothers' lives: reviewing maternal deaths to make motherhood safer. The 7th report of the Confidential Enquiries into Maternal Deaths in the United Kingdom. London: Confidential Enquiry into Maternal and Child Health; 2007.

24. Thornton CE, von Dadelszen P, Makris A, Tooher JM, Ogle RF, Hennessy A. Acute pulmonary oedema as a complication of hypertension during pregnancy. Hypertens Pregnancy 2011;30:169-79.

25. Van Hook JW. Acute respiratory distress syndrome in pregnancy. Semin Perinatol 1997;21:320-7.

26. Cretikos MA, Bellomo R, Hillman K, Chen J, Finfer S, Flabouris A. Respiratory rate: the neglected vital sign. Med J Aust 2008;188:657-9. 